\title{
Impact of Online Consumer Reviews on Buying Intention of Consumers in UK: Need for Cognition as Mediating Role
}

\author{
http://dx.doi.org/10.3991/ijac.v6i2.2910 \\ Ruba Obiedat \\ University of Jordan, Jordan
}

\begin{abstract}
World wide web has offered a strong competitive platform for online marketing which turned out the online shopping important for consumers in today's world particularly those consumers which view the online reviews as effectual conduit of having important product information prior to purchasing decisions. However, the current study attempts to find the impact of online consumer reviews on buying intention of consumers in the context of UK with need for cognition as the mediating role on the basis of elaboration likelihood model developed in 2011. This study followed positivist research philosophy by using quantitative data from 120 consumers in UK who shop online. In conclusion, the current study demonstrated that the buying intention of online consumer who has high cognitive needs was affected by quality of online review or argument as compare to quantity of online argument or reviews. Furthermore, the buying intentions of online consumers with low cognitive need were affected by quantity of rather than quality of arguments. Therefore, hypothesis of current were supported.
\end{abstract}

Index Terms - need for cognition, online review, buying intention, elaboration likelihood model.

\section{INTRODUCTION}

The present study attempts to explore the empirical relationship between the online consumer review and buying intentions of consumers; however the need of cognition is playing a moderating role of this relationship. Internet is providing strong competitive platform for online business and marketing. Particularly, the internet usage as a platform to express the experience related to product or service has turn out to be an imperative marketing contrivance to compete for customer's visits and attentions [7] (Chatterjee, 2001).

According to [10] Kaynar and [1] Amichai-Hamburger (2008), it has been calculated that in all over the world, the number of Internet users is exceeding 10,000 million; nonetheless the information traffic is increasing by fifty percent annually. However, [23] Tedeschi (2010) have been argued that offering consumers a platform to express their experience and monitoring the word-of-mouth (WOM) electronically has befallen a practicable business. Furthermore, WOM is viewed as more plausible as compare to advertisement as it has been perceived as having proved by customers by assessment "people like me" [2] (Allsop et al., 2007).

[11] Keller (2007) has demonstrated that there is decreasing trust on advertisement; however WOM has turn out to be the most powerful communication conduit.
Therefore, online consumer reviews offer electronic form of WOM which has been considered as the trusted source of information regarding product or services for various consumers and consequently potential important sales asset. [11] Keller (2007) further showed this concern as the positive and good consumer online reviews regarding a company's products usually regarded as the preeminent predictors of organizational growth.

According to Amichai-Hamburger and [10] Kaynar (2008) there are two fundamental results in previous research on linking the internet and personality. Firstly, there is difference between the of internet users on internet from their real in world. Secondly, Internet make possible for users to enhance their psychosomatic well-being by anonymity and further through high extent of control. Nonetheless, a few number of research studies have been conducted to find out the impact of online messages and evaluations of potential consumers on the buying intention for a specific product [7] (Chatterjee, 2001).

Therefore, the current study aims to broaden the research by understanding the online consumers. [4] Cacioppo and [16] Petty (1982) explain the cognition need as the factor of personality which is generally used to measure and explain the tendency of individual for information [1] (Amichai-Hamburger et al., 2007). Consequently, Cognition need was adopted in current study as moderator in exploring the impact of online reviews of consumers on buying intentions of consumers.

To empirically explore the hypothesized relationship between the online consumer reviews and consumer buying intention, the current study has used the theoretical perspective of "Elaboration likelihood model (ELM)" which has been established by [16] Petty and [4] Cacioppo (1981, 2011). Furthermore, [15] Park et al., (2007) has also supported this model by using ELM to investigate the influence of online consumer reviews on the s of influence of online consumers.

However, an experimental research study has also been conducted to explore the moderating role of involvement in investigating persuasion route. In this study, it has been reported that quantity and quality of online consumer reviews have a strong impact on buying intentions of consumers (PI), on the other hand, the consumer who are low involved are usually affected by quantity of online reviews as compare to quality of online reviews, nonetheless, the consumer who are highly involved are influenced by the high quality of online reviews as compare to quantity of review. [15] Park et al., (2007) investigated the impacts of online reviews through ELM, but their results were not consistent with pervious 
ELM research studies. For that reason, more research is needed to understand the impacts of online consumer reviews. Consequently, the current research had objective to extend the ELM application into emerging research domain for online consumer reviews. The knowledge contribution current research study is in marketing and management literature in the domain of electronic marketing through the introduction of ELM theory as reference.

In conclusion, the current study demonstrated that the buying intention of online consumer who has high cognitive needs was affected by quality of online review or argument as compare to quantity of online argument or reviews. Furthermore, the buying intentions of online consumers with low cognitive need were affected by quantity of rather than quality of arguments. Therefore, hypothesis of current were supported. The next section is literature review.

\section{LITERATURE REVIEW}

This section will shed light on underpinning theories and model related to current research area.

\section{A. Online consumer reviews and buying intention of consumers}

According to [15] Park et al., (2007) the satisfaction of consumers increases due to increase in the quality level of consumer online reviews, ultimately the consumer satisfaction lead to higher buying intentions of consumers. The research area also emphasize on the quality of consumer online reviews. Online reviews which are objective and easily understandable are regarded as more influential in changing the $\mathrm{s}$ and intentions of consumers as compare to those reviews which are weak and depicts the subjective and emotional style [4] [20] (Cacioppo, Petty and Schumann, 1983; Petty and Cacioppo, 1984). Therefore, the online reviews that contain fact supported knowledge and argument which are easily understandable are more swaying as compare to those reviews which show vague comments. Thus, it can be concluded that favorable of consumer can be produced when online review of high quality is developed. This lead to the first hypothesis of this study which is as follows:

Hypothesis 1: There is significant relationship between high quality of online consumer review and buying intention of consumers in UK

Online consumer reviews are regarded as a new type of recommender which is same to messenger of conventional communication through WOM word-of-mouth [7] (Chatterjee, 2001). Nevertheless, the people who contribute in online consumer reviews are usually previous users who want to stay anonymous; despite this fact the sources of conventional word-of-mouth (WOM) recommendations are usually known people. However, in the case if online consumer reviews, lack of trustworthiness encourages online consumers to use these cues in their formulation. Another concern about the online consumer reviews are the quantity (Number of online consumer reviews) which is generally use to identify the popularity of product or services for the reason that it is regarded as to demonstrated the market performance and the fame of specific products and services [13] (Mayzlin and Chevalier, 2006). Furthermore, the quantity of online consumer reviews might also offer the reference point to make stronger the confidence of online consumers by decreasing the uncomfortable risk feelings exposure [3] (Buttle, 1998). In last, it can be said that online shoppers can recognize that greater the number of reviews, greater will be the fame and importance of product or service. Thus, this study formulates the following hypothesis of this study.

Hypothesis 2: There is significant relationship between high quantity of online consumer review and buying intention of consumers in UK.

\section{B. Elaboration likelihood model}

Numerous theories and models have been used to investigate the influence and role of the procedures in shaping the perception of consumer buying intentions, these theories are known as dual-process theories. According to these dual-process theories, formation of attitudes do not based on effortful procedure of influential facts and information, but at times might be based on less effortful procedures of heuristic prompts. Furthermore, theories of Dual-process categories the conditions in which there are two major procedures which can probable to happens [6] (Chaiken and Trope, 2010). According to [16] [19] Petty and Cacioppo $(1981,2011)$ the elaboration likelihood model (ELM) offers a very effectual framework for understanding the efficiency of influential communication [12] [22] (Sher and Lee, 2009; Lee, 2009).

According to ELM, Petty and [4] Cacioppo (1981, 2011) argued that of consumers might change due to two different routes of persuade which is given below:

\section{The central route}

\section{The peripheral route}

These routes are two different processes in terms of amount of thinking process of "elaboration" or information. Those people who adopt the central route consider significantly about issue-associated arguments and inspect the relevance and merits of those valuable arguments previous to form an attitude regarding the product or advertisement. Conversely, those people who adopt the peripheral route usually make a smaller amount cognitive effort in formation of their attitudes towards a specific product or service and generally depend on when forming attitude and depends on shortcuts for example the number of online consumer reviews and corporeal attractiveness of endorsers. However, [18] Petty and Cacioppo (2011) argued that in the ELM, it has been posited that $s$ of consumers might change through that central route is more predictive and enduring of consumer as compare to change attitude change induced by the peripheral route for the reason that the former route have its bases on thoughtful and deliberate consideration of pertinent arguments [18] (Petty and Cacioppo, 2011).

However, Wegener and [21] Petty (2010) demonstrated that consumers who are high elaboration likelihood state are potentially connected in solicitous processing of knowledge and information and generally probable to be convinced by the quality of argument. In contrast, consumers who are low in elaboration likelihood state be inclined to form their change on tangential cues.

Therefore, Elaboration likelihood plays moderating role of quality of arguments and tangential cues on the consumer regarding any specific product and services. In accordance with ELM, elaboration likelihood find out through the motivation and capability to elaborate of a consumers. On the other hand, motivation is known as the 
personal relevance to consumer for the influential online consumer review while capability is known as the pervious expertise of consumers with the regarding specific product or services. Even though every consumer are different from each other vary in their motivation and capabilities to elaborate. Thus, the motivation is also playing moderation role in this study and named as cognition need thus, cognition need is adopted as moderating variable of current study and underpinning literature is given in next section regarding cognition need.

\section{Cognition Need}

The association of personality variables and of consumers has been studied in research with great interest as the marketing discipline has been developed [9] (Haugtvedt, [16] Petty, and Cacioppo, 1992). Cacioppo and [17] Petty (1982) has been demonstrated cognition need as a significant variable of personality which refers to enjoy, engage in effortful activity of cognition, even though these personal characteristic can be affected by numerous certain situational factors (Cacioppo et al., 1996). According to [24] Tuten \& Bosnjak (2001) demonstrated that personal differences is referred as cognition need, furthermore, the cognition need fall in continuum of bipolar which is anchored at high and low on both sides. Consumers who have low cognition need do not enjoy effort of cognition and mostly depends on others prefer to opinions of experts in case of complex issues and handling these issues. These consumers potentially base their behavior on straightforward cues for example the attraction of sources [5] (Cacioppo, Petty and Goldman, 1981) or the quantity of online consumer reviews provided by messages [5] (Petty \& Cacioppo, 1984).

On the other hand, consumers who have high cognitive needs are usually attracted by available cognitive resource and are potentially use efficient and methodological conventions to analyze the related information. Thus the attributes of these consumers can be defined as highly intrinsic, curious and motivated [14] (Camp, Olson and Fuller, 1984). As a result, these consumers are logically motivated to seek information and consequently acquire this information.

Immense research has been done to find the impact of cognition need in diverse situations for instance memory recall, knowledge and cognitive tests and use of inter [1] (Amichai-Hamburger et al., 2007; [10] Kaynar and Amichai-Hamburger, 2008 ; Cacioppo et al., 1996). Online reviews have become an important tool of information particularly online consumers. On the other hand, there is little research has been conducted to find the cognition in the area of online reviews. According to the ELM, the behaviors of consumer are based on the peripheral and central route which further depends on the cognition need. Thus, the third hypothesis of current study is as follows:

Hypothesis 3: The buying intention of consumers with high level of need cognition will be affected by quality rather than quantity of online consumer reviews in UK.

As the quantity of online reviews regarding a specific product depicts the fame of that product for the reason that the quantity of online reviews demonstrated the number of consumer who are interested in product or may use the product [7] (Chatterjee, 2001).However, according to the ELM, consumer who have low cognition need put less effort to analyze the information, thus these consumer tend to form their behaviors on tangential cues, for example the outlook of product or the number of online reviews, thus the fourth hypothesis of current study is as follows :

Hypothesis 4: The buying intention of consumers with low level of need cognition will be affected by quantity rather than quality of online consumer reviews in UK.

\section{THEORETICAL FRAMEWORK}

This section will demonstrate the theoretical framework of study which is as follows:

Independent variable

Dependent variable

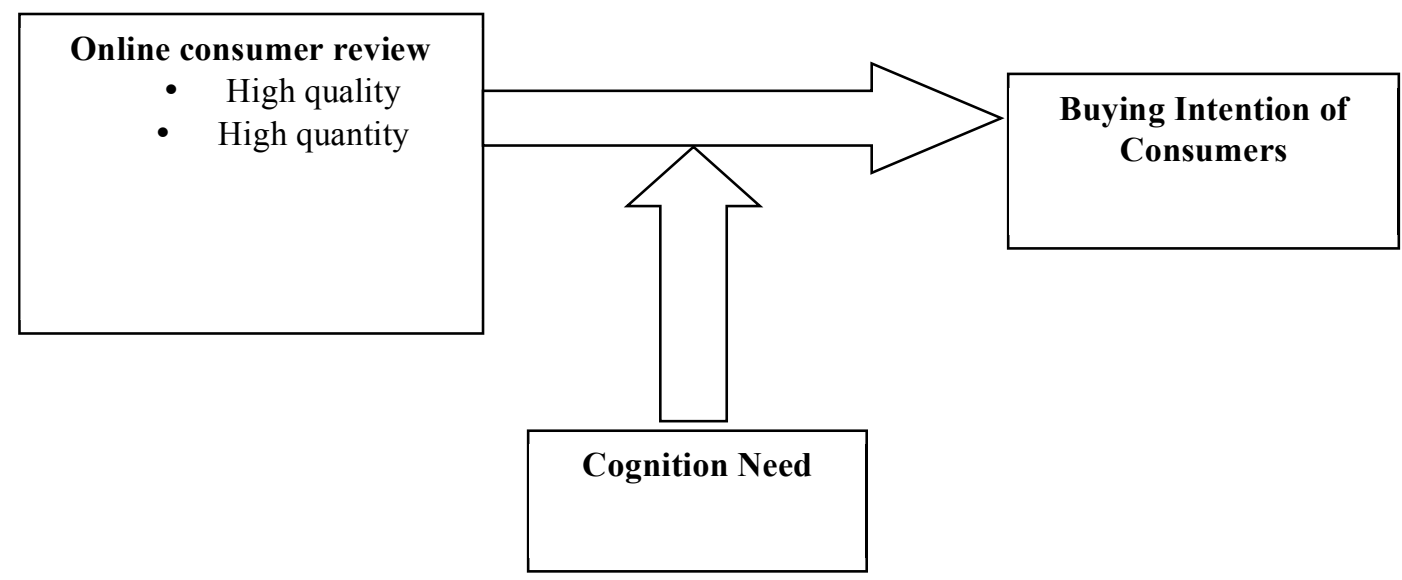

Figure 1. Impact of Online Consumer Reviews on buying Intention of Consumers in UK: Need for cognition as the moderating role. Source: [15] Park et al., (2007) [16] [18] Petty and Cacioppo (1981, 2011) 


\section{HYPOTHESIS FORMULATION}

Hypothesis 1: There is significant relationship between high quality of online consumer review and buying intention of consumers in UK

Hypothesis 2: There is significant relationship between high quantity of online consumer review and buying intention of consumers in UK

Hypothesis 3: The buying intention of consumers with high level of need cognition will be affected by quality rather than quantity of online consumer reviews in UK.

Hypothesis 4: The buying intention of consumers with low level of need cognition will be affected by quantity rather than quality of online consumer reviews in UK.

\section{METHODOLOGY}

The current study followed positivist research philosophy by using quantitative data from 120 respondents. The units of analyses are those customers, consumers, and end users who use to shop products from the internet stores. A self-administered 5 point Likert scale questionnaire was used in order to collect the data. The questionnaire was adapted from [15] Park et al., (2007) therefore there the cronbach alpha was already tested. The questionnaire was distributed through emails and by using a website "monkey survey" a survey was created and spread through the UK online market. Total 145 questionnaires were distributed among customers, consumers, and end users who use to shop products from the internet stores of UK industry through e-mail and get the response of $120 / 145$ which was good enough to carry on this research study. Further deductive approach was applied in current research. The nature of study was cross-sectional study due to time limitation and nature of study. Further data was gathered and analyzed in SPSS Statistical Package 17.

\section{DATA ANALYSIS AND RESULTS}

The participants of current study have been categorized as low or high in cognitive need through median split as given below:

\begin{tabular}{|l|c|}
\hline Median & 72 \\
\hline Median for low cognitive need & 66.2 \\
\hline Median for high cognitive need & 79.6 \\
\hline
\end{tabular}

In table 1, the descriptive statistics has been summarized for purchasing intention of participants.

TABLE I

STANDARD DEVIATION AND MEANS OF BUYING INTENTION

\begin{tabular}{|c|c|c|c|c|}
\hline & $\begin{array}{l}\text { low } \\
\text { need }\end{array}$ & cognitive & high cogn & tive need \\
\hline & $\begin{array}{l}\text { Week } \\
\text { AQ }\end{array}$ & $\begin{array}{l}\text { Strong } \\
\text { AQ }\end{array}$ & $\begin{array}{l}\text { Week } \\
\mathrm{AQ}^{\text {Wen }}\end{array}$ & $\begin{array}{l}\text { Strong } \\
\text { AQ }\end{array}$ \\
\hline $\begin{array}{r}\text { Small } \\
\text { quantity }\end{array}$ & $\begin{array}{c}3.74 \\
(1.12)\end{array}$ & $\begin{array}{c}3.68 \\
(1.04)\end{array}$ & $3.98(1.10$ & $\begin{array}{c}4.46 \\
(1.30)\end{array}$ \\
\hline & $\mathrm{n}=10$ & $\mathrm{n}=16$ & $\mathrm{n}=24$ & $\mathrm{n}=10$ \\
\hline $\begin{array}{r}\text { Large } \\
\text { quantity }\end{array}$ & $\begin{array}{r}4.23 \\
(0.84)\end{array}$ & $\begin{array}{r}4.37 \\
(0.96)\end{array}$ & $\begin{array}{r}3.70 \\
(1.50)\end{array}$ & $\begin{array}{c}4.62 \\
(0.79)\end{array}$ \\
\hline & $\mathrm{n}=18$ & $n=26$ & $\mathrm{n}=14$ & $\mathrm{n}=2$ \\
\hline
\end{tabular}

Note: AQ is Argument quality or the quality of online review 3-factor ANOVA was tested from the data which further demonstrated the imperative impact of quality of argument as $\mathrm{F}(1,60)=7.890$ at $\mathrm{p}<0.05$ and ANOVA also depicted that there is imperative impact of review quantity $F(1,60)=4.090$ at $p<0.05$. Thus, it can be said that high quality of online reviews is positively related to the buying intentions of consumer who are online consumers. Thus, Hypothesis 1 and 2 has been accepted in current study.

In addition to that, as hypothesized by ELM that there is positive relationship between the quality of online reviews and cognitive need, this statement was also supported by ANOVA as $\mathrm{F}(1,60)=7.213, \mathrm{p}<0.05$. Thus, it can be concluded from results that, the consumer who have high cognitive usually takes the central way or route to formulate the buying intention for a specific product or services. Thus, the results has demonstrated that the respondents of study who have high cognitive need depicts more positive impact after seeing the strong quality of any argument $(\mathrm{M}=4.54)$ as compare to weak quality of argument $(\mathrm{M}=3.76)$ as $\mathrm{F}(1,60)=13.952$, p < 0.001 , however the behaviors of respondents who have low cognitive need depicts to strong $(M=3.99)$ and weak $(\mathrm{M}=4.02)$ quality of argument or online reviews are not significantly different.

However, the relationship of Cognitive need and significant quantity of online reviews has been depicted from ANOVA as F $(1,60)=7.930, p<0.05]$. Particularly, the major impact of online review quantity was also shown by Cognitive need and significant quantity of online reviews. Nonetheless, the results of current study were fairly supported by ELM. It can be stated that consumer who have low cognitive need are usually adopt the peripheral route to formulate the buying intentions for specific product or services.

The result of current study has shown that consumers who have low cognitive need depict positive attitude towards large number of online reviews $(\mathrm{M}=4.30)$ as compare to small number of online review as $(\mathrm{M}=3.71 \mathrm{~F}$ $(1,60)=12.174, p<0.001$, however the of high cognitive need were not different for small or large quantity of online reviews $(\mathrm{M}=4.17)$.

In conclusion, the current study have demonstrated that the buying intention of online consumer who has high cognitive needs was effected by quality of online review or argument as compare to quantity of online argument or reviews. Furthermore, the buying intentions of online consumers with low cognitive need were affected by quantity of rather than quality of arguments. Therefore, hypothesis 3 and 4 were also supported in current study.

\section{DISCUSSION ON HYPOTHESIS TESTING}

This section presents the discussion on each hypothesis which we propose on the basis of substantive literature. Empirical reflection on each hypothesis will be analyzed to decide whether hypothesis projected have a significant or insignificant relationship. As the results of 3 Factor Anova Testing and P-value it can be said that high quality of online reviews is positively related to the buying intentions of consumer who are online consumers. Also the descriptive stats depicts the 4.37 value for high quality consumer reviews so on the basis if these results we accept the Hypothesis 1, and we can say that high quality 
of consumer reviews have strong impact on consumer purchase intensions in UK.

Similarly the 3 Factor Anova testing result for Hypothesis 2 is 4.09 and the result of descriptive tests is 4.62 which is also sufficient to support the $\mathrm{H} 2$ and to prove that high quantity of consumer reviews have also significant positive impact on the consumer purchase intensions in UK. This $\mathrm{H} 2$ is also supported by the previous literature, as the findings of the study [16] (Petty and Cacioppo, 2011), and Wegener and Petty (2010) concluded that consumers who read consumer reviews large in quantity they are also inclined towards having strong influence regarding the purchase of that products in UK.

Similarly the relationship of Cognitive need and significant quantity of online reviews has been depicted from ANOVA as $F(1,60)=7.930, p<0.05]$. It shows particularly, the buying intention of consumers with high level of need cognition will be affected by quality rather than quantity of online consumer reviews in UK. This hypothesis 3 is also supported by the previous literature as [24] Tuten \& Bosnjak (2001) demonstrated that personal differences is referred as cognition need, furthermore, the cognition need have the strong impact for those customers which are more inclined towards the quality rather than quantity.

The Hypothesis 4 results are $\mathrm{F}(1,60)=12.174, \mathrm{p}<$ 0.001 . It shows particularly, the buying intention of consumers with low level of need cognition will be affected by quantity rather than quality of online consumer reviews in UK. Therefore, this hypothesis 4 is also supported by the previous studies [1] (AmichaiHamburger et al., 2007; [10] Kaynar and AmichaiHamburger, 2008; Cacioppo et al., 1996) findings were similar and they found that the consumers with low need of cognition can be affected by the high quantity of online consumer reviews in UK.

\section{CONCLUSION}

Online consumer review is one of the most imperative communication ways in today's business world. Immense research has demonstrated that online consumer reviews have an important impact on the sales of corporation (Mayzli and Chevalier, 2006). Consequently, online consumer reviews should be manage and handled in a good way and should be incorporated in communication marketing strategy of organization. The present study attempts to explore the empirical relationship between the online consumer review and buying intentions of consumers; however the need of cognition is playing a moderating role of this relationship. There were four major findings of current study that includes: Firstly, the high quality of consumer reviews is positively linked with the buying intention of online consumers. thus, the consumer reviews which have high quality of argument are more objective, therefore, high quality argument were more influencing as compare to low quality of review argument that are usually emotional and subjective. Secondly, the current study revealed that large of number and quantity of online reviews is positively linked with high intention of purchasing by consumers. Thus, the behavior of online consumers turns out to be more positive as the quantity of online reviews goes on increasing. Thus, the high quantity of consumer reviews indicates the quality and fame of product and therefore increases the intention of consumer to buy. Moreover, the major impact of quality of argument is qualified by cognitive need and argument. Consumers which have high cognitive take central route to formulate the buying intention, therefore the consumers are influenced by review quality. Hence the results of current study were supported by the research literature of ELM by increasing the application of ELM to online attributes of consumers. According to the central route, marketing professionals should carefully, regard the correct match among the consumer levels and digital demonstration of online consumer reviews. In last, the results of current study was supported by theory of ELM, as the major impact of quantity of online consumer reviews was qualified by cognitive need and quantity of reviews. The consumers who have low cognitive need usually intended to adopt the peripheral route to formulate the buying intention for a product, therefore these consumer were influenced by the quantity of online consumer reviews as compare to quality of consumer reviews.

This result was contributed to understand the system underpinning the impact of online consumer reviews. For marketing professional and developers of software, the, the peripheral route viewpoint depicts the significance of creating numerous consumer reviews for people who have low cognitive need. In conclusion, the current study have demonstrated that the buying intention of online consumer who has high cognitive needs was effected by quality of online review or argument as compare to quantity of online argument or reviews. Furthermore, the buying intentions of online consumers with low cognitive need were affected by quantity of rather than quality of arguments.

\section{REFERENCES}

[1] Amichai-Hamburger, Y., Kaynar, O., \& Fine, A. (2007). The effects of need for cognition on Internet use. Computers in Human, 23(1), 880-891. http://dx.doi.org/10.1016/j.chb. 2006.03.002

[2] Allsop, D. T., Bassett, B. R., \& Hoskins, J. A. (2007). Word-ofmouth research: Principles and applications. Journal of Advertising Research, 47, 398-411. http://dx.doi.org/10.2501/ S0021849907070419

[3] Buttle, F. A. (1998). Word of mouth: Understanding and managing referral marketing. Journal of Strategic Marketing, 6(3), 241-254. http://dx.doi.org/10.1080/096525498346658

[4] Cacioppo, J. T., \& Petty, R. E. (1982). The need for cognition. Journal of Personality and Social Psychology, 42(1), 116-131. http://dx.doi.org/10.1037/0022-3514.42.1.116

[5] Cacioppo, J. T., Petty, R. E., Feinstein, J. A., \& Jarvis, W. B. G. (1996). Dispositional differences in cognitive motivation: The life and times of individuals varying in need for cognition. Psychological Bulletin, 119(2), 197-253. http://dx.doi.org/10.1037/0033-2909.119.2.197

[6] Chaiken, S., \& Trope, Y. (2010). Dual-process theories in social psychology. New York: Guilford.

[7] Chatterjee, P. (2001). Online reviews: Do consumers use them? Advances in Consumer Research, 28, 129-133.

[8] Girard, T., Silverblatt, R., \& Korgaonkar, P. (2002). Influence of product class on preference for shopping on the Internet. Journal of Computer-Mediated Communication, 8, 101-120.

[9] Haugtvedt, C. P., Petty, R. E., \& Cacioppo, J. T. (1992). Need for cognition and advertising: Understanding the role of personality variables in consumer. Journal of Consumer Psychology, 1, 239260. http://dx.doi.org/10.1016/S1057-7408(08)80038-1

[10] Kaynar, O., \& Amichai-Hamburger, Y. (2008). The effects of cognition on Internet use revisited. Computers in Human , 24(2), 361-371. http://dx.doi.org/10.1016/j.chb.2007.01.033 
PAPER

IMPACT OF ONLINE CONSUMER REVIEWS ON BUYING INTENTION OF CONSUMERS IN UK

[11] Keller, E. (2007). Unleashing the power of word of mouth: Creating brand advocacy to drive growth. Journal of Advertising Research, 47(4), 448-452. http://dx.doi.org/ $10.2501 / \mathrm{S} 0021849907070468$

[12] Lee, S. H. (2009). How do online reviews affect purchasing intention? African Journal of Business Management, 3, 576-581.

[13] Mayzlin, D., \& Chevalier, J. A. (2006). The effect of word of mouth on sales: Online book reviews. Journal of Marketing Research, 43(3), 345-354. http://dx.doi.org/10.1509/ jmkr.43.3.345

[14] Olson, K., Camp, C., \& Fuller, D. (1984). Curiosity and need for cognition. Psychological Reports, 54(1), 71-74. http://dx.doi.org/10.2466/pr0.1984.54.1.71

[15] Park, D-H., Lee, J., \& Han, I. (2007). The effect of on-line consumer reviews on consumer purchasing intention: The moderating role of involvement. International Journal of Electronic Commerce, 11(4), 125-148. http://dx.doi.org/ 10.2753/JEC1086-4415110405

[16] Petty, R. E., \& Cacioppo, J. T. (1981). Attitudes and persuasion: Classic and contemporary approaches. Dubuque, IA: Brown.

[17] Petty, R. E., \& Cacioppo, J. T. (1984). The effects of involvement on response to argument quantity and quality: Central and peripheral routes to persuasion. Journal of Personality and Social Psychology, 46(1), 69-81. http://dx.doi.org/10.1037/00223514.46.1.69

[18] Petty, R. E., \& Cacioppo, J. T. (2011). Communication and persuasion: Central and peripheral routes to attitude change. New York: Springer-Verlag.

[19] Petty, R. E., Cacioppo, J. T., \& Goldman, R. (1981). Personal involvement as a determinant of argument-based persuasion. Journal of Personality and Social Psychology, 41(5), 847-855. http://dx.doi.org/10.1037/0022-3514.41.5.847
[20] Petty, R. E., Cacioppo, J. T., \& Schumann, D. (1983). Central and peripheral routes to advertising effectiveness: The moderating role of involvement. Journal of Consumer Research, 10, 135- 146. http://dx.doi.org/10.1086/208954

[21] Petty, R. E., \& Wegener, D. T. (2010). The elaboration likelihood model: Current status and controversies. In S. Chaiken \& Y. Trope (Eds.), Dual-process theories in social psychology. New York: Guilford.

[22] Sher, P. J., \& Lee, S. H. (2009). Consumer skepticism and online reviews: An elaboration likelihood model perspective. Social and Personality: An international journal, 37(1), 137-144. http://dx.doi.org/10.2224/sbp.2009.37.1.137

[23] Tedeschi, B. (2010). Consumer products and firms are being reviewed on more web sites, some featuring comments from anyone with an opinion. New York Times, Section B, p. 1.

[24] Tuten, T., \& Bosnjak, M. (2001). Understanding differences in web usage: The role of need for cognition and the five factor model of personality. Social and Personality: An international journal, 29(4), 391-398. http://dx.doi.org/ $10.2224 / \mathrm{sbp} .2001 .29 .4 .391$

\section{AUTHOR}

Ruba Obiedat is from Department of Business Information Technology, The University of Jordan. Dr. Obiedat is an Assistant professor at the University of Jordan. Her main interests in research are business intelligence and data mining. She graduated from university of Salento in Italy. (o.harfoushi01@gmail.com).

Manuscript received 12 June 2013. Published as re-submitted by the author 23 July 2013. 